\title{
Acting parentally: an argument against sex selection
}

\section{R McDougall}

\section{See end of article for authors' affiliations \\ Correspondence to: R McDougall, Mansfield College, Oxford OX1 3TF, UK; rosalind.mcdougall@ mansfield.ox.ac.uk}

Received 16 March 2004 In revised form 12 October 2004 Accepted for publication 11 January 2005
J Med Ethics 2005;31:601-605. doi: 10.1136/jme.2004.008813

The Human Fertilisation and Embryology Authority's (HFEA) recent restrictive recommendations on sex selection have highlighted the need for consideration of the plausibility of ethical arguments against sex selection. In this paper, the author suggests a parental virtues approach to some questions of reproductive ethics (including sex selection) as a superior alternative to an exclusively harm focused approach such as the procreative liberty framework. The author formulates a virtue ethics argument against sex selection based on the idea that acceptance is a character trait of the good parent. It is concluded that, because the argument presented posits a wrong in the sex selecting agent's action that is not a harm, the argument could not function as a justification of the HFEA's restrictive position in light of their explicit commitment to procreative liberty; it does, however, suggest that ethical approaches focused exclusively on harm fail to capture all the relevant moral considerations and thus that we should look beyond such approaches. lis November 2003, the Human Fertilisation and Embryology Authority (HFEA) in the United Kingdom released a report on its review of sex selection. ${ }^{1}$ The review focused particularly on sperm sorting and preimplantation genetic diagnosis as sex selection techniques. The report's key recommendation was that sex selection should only be available in "cases in which there is a clear and overriding medical justification", (HFEA, para 147) referring to the avoidance of sex linked genetic conditions. As Harris has argued, ${ }^{2}$ and as a close reading of the document makes clear, this position is essentially based on market research rather than systematic ethical analysis. The HFEA's report and the preceding consultation document do, however, refer to a number of ethical arguments against sex selection. These include: sex selection as playing God; ${ }^{3}$ sex selection as an inappropriate use of medical resources; (HFEA, ${ }^{3}$ para 29) the potential for unequal access to sex selection technology; (HFEA, ${ }^{3}$ paras 90-1) possible resultant disruption of the sex ratio; (HFEA, ${ }^{1}$ para 78 ) (HFEA, ${ }^{3}$ paras $85-6$ ) stepping onto the slippery slope to designer babies; (HFEA, ${ }^{1}$ para 29) (HFEA, ${ }^{3}$ paras 92-5) gender discrimination; (HFEA, ${ }^{1}$ para 29) (HFEA, ${ }^{3}$ paras 81-4) and negative effects on the welfare of children produced using sex selection technology (HFEA, para 139) (HFEA, ${ }^{3}$ paras 87-9).

My aim in this paper is to formulate a different argument against sex selection, one not mentioned in the HFEA material. The argument draws on a virtue ethics framework and is based on the idea that the willingness to accept one's child, regardless of characteristics such as the child's sex, is a trait of the good parent. In section 1 I briefly outline and argue for a virtue ethics approach to some questions in reproductive ethics. I posit a criterion of right parental action that claims that an act is right if it is what the virtuous parent would do in the circumstances, where the parental virtues are defined as characteristics conducive to the flourishing of the child. In section $2 \mathrm{I}$ argue that sex selection is morally impermissible in light of the parental virtue of acceptance. In section 3 I consider some possible objections to this argument. Throughout the paper I assume the UK context of relative equality between the sexes, and thus accept that the argument's force is limited to such contexts. I conclude with some thoughts on policy implications of the argument; I suggest that the argument presented is a basis for moral condemnation of sex selection, but still falls short in terms of providing an ethical justification for the HFEA's restrictive position in light of the HFEA's explicit commitment to procreative liberty. Under a framework privileging procreative liberty, the wrong involved in sex selection must be a harm based wrong in order to justify restriction, and this is not the type of wrong posited by the argument against sex selection that I put forward. The fact that there are ethical considerations that remain uncaptured by an exclusively harm focused approach such as procreative liberty gives us good reason to look beyond this type of framework for a more comprehensive way of assessing the moral status of particular reproductive choices.

\section{SECTION 1: ADOPTING A VIRTUE ETHICS APPROACH TO A QUESTION OF REPRODUCTIVE ETHICS}

The prevailing approach to ethical questions around reproduction is an approach based on the notion of the primacy of parental procreative liberty. Murray has called this procreative liberty approach "the regnant contemporary framework for thinking about the ethics of reproductive technologies". ${ }^{4}$ The procreative liberty framework is a harm based approach to reproductive ethics that posits a criterion of right action along the lines of "an action is right if it causes no significant harm to others"; under this framework a reproductive choice is morally permissible if it is not (significantly) harmful. The classic description of this approach is provided by Robertson. ${ }^{5}$ The approach is based on the idea that reproduction is such a personal, self expressive decision that people are entitled to great freedom in this area of life. Robertson writes, for example, that "because of the centrality of reproduction to personal identity, meaning, and dignity...the liberty to procreate [is] an important moral right" (Robertson, ${ }^{5}$ p 30). Dworkin gives a similar justification. ${ }^{6}$ The influence of this approach is demonstrated by its invocation in the HFEA material. The HFEA explicitly commits itself to respecting the principle of procreative liberty, stating that "the decision to have children...is an area of private life in which people are generally best left to make their own choices and in which the state should intervene only to prevent the occurrence of serious harms, and only where this intervention in nonintrusive and likely to be effective" (HFEA, ${ }^{1}$ para 132).

Abbreviation: HFEA, Human Fertilisation and Embryology Authority 
Although the extent to which the HFEA's reasoning and conclusions in fact align with a procreative liberty outlook is questionable, ${ }^{2}$ the HFEA's emphasis on potential harms as the crucial relevant factors is clear.

Despite its pervasive influence, the harm focused procreative liberty approach faces a fundamental difficulty. The difficulty is the non-identity problem described by Parfit. $^{7}$ The non-identity problem relates to the fact that so long as they have lives worth living, we do not harm the people whom we bring into existence. Had we acted otherwise, these people would not exist at all and thus our action cannot be worse for these people. Because reproductive decisions are often decisions that determine who will exist, the idea of harm to the child produced by a particular reproductive decision is problematic as the alternative for that child is non-existence. The name "non-identity problem" refers to the fact that the person created when the agent makes the "better" reproductive decision is a different person from the one that would exist if the agent made the "worse" decision. Thus, in making the "worse" decision, the agent cannot be said to harm the resulting child.

This non-identity problem effectively precludes meaningful consideration under a harm focused approach of the child produced by a particular reproductive decision; this is the fundamental difficulty for an approach such as the procreative liberty framework. So long as the child's life is preferable to non-existence, bringing the child into existence is deemed morally permissible. This sets an extremely low standard for morally permissible reproduction. (For critiques of the low threshold for moral acceptability associated with the procreative liberty framework see Murray, ${ }^{4} \mathrm{p} 42$, Lauritzen ${ }^{8}$ and Steinbock. ${ }^{9}$ ) For example, knowingly producing a child who was inevitably destined for a life of abuse or a child whose life would consist almost entirely of suffering as a result of a crippling medical condition would both be deemed morally permissible actions by parents (at least in terms of harm to the child produced; significant harms to existing people could potentially deem such actions impermissible). The intuitively problematic nature of condoning such reproductive choices as innocuous with respect to the children produced points to the deep problem that the non-identity problem produces for any exclusively harm focused approach.

I will outline a potential alternative to the harm focused procreative liberty approach, drawing on ideas from virtue ethics. The parental virtue framework that I will outline moves away from this notion of harm as crucial and thus avoids the non-identity problem and the associated implausibly low threshold for morally acceptable reproductive decisions. Because the alternative framework's criterion of right action invokes the agent's character rather than putative harms associated with the action, the fact that the child who may be the locus of a harm does not yet exist is unproblematic.

The term "virtue ethics" covers a number of ethical theories, all of which claim primacy for character in the justification of right action. (For a full account of the positive claims of virtue ethics see Oakley's article. ${ }^{10}$ ) Virtue ethics posits the following criterion of right action: an action is right if and only if it is what a virtuous agent would do in the circumstances. ${ }^{11}$ As Oakley writes: "what makes the action right [under virtue ethics] is that it is what a person with a virtuous character would do" [Oakley's italics] (Oakley, ${ }^{10}$ p 130). Virtue ethics also makes the related claim that the virtuous person is one who has and exercises the virtues. This claim decisively differentiates virtue ethics from Kantianism and consequentialism, both of which have room for the concept of the virtuous person but define virtue in terms of action in accordance with particular rules such as the categorical imperative or the maximisation of wellbeing
(Hursthouse, ${ }^{11} \mathrm{p} 23$ ). Under virtue ethics, virtue is prior to the definition of right action rather than derivative from it.

Thus virtue ethics fills out the idea of the virtuous person in a way that is independent of the virtuous person's disposition to act rightly. One strand of virtue ethics posits the virtuous person as one who has character traits conducive to human flourishing; in Oakley's words, this approach sees "the content of virtuous character...[a]s determined by what we need, or what we are, qua human beings" [Oakley's italics] (Oakley, ${ }^{10} \mathrm{p}$ 133). Hursthouse identifies the question "How am I to live well?" as the basis of this approach. ${ }^{12}$ Hursthouse argues that a moral conclusion emerges from the answer to this non-moral question; from an understanding of what makes a human life go well, we can articulate a set of character traits that are conducive to living well. Hursthouse writes that:

as human beings, we naturally have certain emotions and tendencies, and... it is simply a brute fact (made up of a vastly complex set of other facts) that given that we are as we naturally are, we can only flourish/be happy/ successful by developing those character traits that are called the virtues-courage, justice, benevolence and so on [Hursthouse's italics] (Hursthouse, ${ }^{12}$ p 226).

Hursthouse uses the examples of generosity, honesty, and courage as illustrative, arguing that facts about human life make these character traits conducive to human flourishing: generosity promotes flourishing because humans "are naturally sociable creatures who like to have friends and want to be loved by friends and family"; honesty promotes flourishing for similar reasons and because "there are likely to be occasions in our lives when we need to be believed", and courage promotes flourishing because humans fear the pain and death to which they are inevitably subject (Hursthouse, ${ }^{12}$ pp 226-8). So the position is that there are certain character traits that promote human flourishing, taking some facts about human life as immutably given, and that these character traits are the virtues. Combining this set of flourishing conducive traits with the innocuous normative assumption that it is morally important that human lives go well, we arrive at the moral conclusion that we should have and exercise these character traits; we should act in accordance with the virtues. The claim is not that those people with the flourishing conducive character traits inevitably flourish, rather, as Hursthouse puts it, that "[v]irtue is the only reliable bet" (Hursthouse, ${ }^{12}$ p 230).

The key virtue ethics claims that I have outlined can therefore be summarised as follows:

- Criterion of right action-an action is right if and only if it is what a virtuous agent would do in the circumstances;

- Origin of the virtues-virtues are character traits conducive to human flourishing, based on immutable facts about human life.

Versions of these claims specific to the realm of parental action (which I will take to include reproduction and rearing) can be articulated:

- Criterion of right parental action-an action is right if and only if it is what a virtuous parent would do in the circumstances;

- Origin of the parental virtues-parental virtues are character traits conducive to the flourishing of the child, based on immutable facts about human reproduction and rearing. 
I will refer to these claims as the parental virtues approach. These parenting specific claims involve the additional assumption that the primary purpose of parenthood is the flourishing of the child. In the general context we made the baseline assumption that the purpose of human agents is the promotion of human flourishing; in the parental context, the assumption is that the primary purpose of a parent is the flourishing of his or her child. The idea is that this purpose is the primary necessary element of the parental role. It may be objected that positing parenting as exclusively aimed at the flourishing of the child is too simplistic. Becoming a parent is also, it might be argued, partly and justifiably a self directed project. This objection can be accommodated, however, in a view positing the purpose of parenting as the flourishing of the child. The parent's interests are not excluded on such a view once it is acknowledged that parental wellbeing contributes to the flourishing of that parent's child. Positing the flourishing of the child as the purpose of parenthood does not obviate the importance of the parent's own interests; it does not make the good parent one whose own interests are inevitably martyred to the project of the maximal flourishing of his or her child. That the flourishing of the child is the primary commitment associated with the parental role is, however, suggested by the intuitive implausibility of the low threshold implied by an exclusively harm focused approach discussed earlier. There seems to be something unparental about an agent who creates a child with no chance of flourishing, purely to satisfy his or her own desire to have a child. So the assumption that the primary purpose of parenthood is the flourishing of one's child seems a defensible one.

Having articulated the above criterion of right parental action, the following question then arises: how relevant is this criterion to questions of reproductive ethics such as the moral status of sex selection? For not all questions of reproductive ethics seem rightly described as questions about parental action. It seems odd, for example, to posit a criterion of right parental action as relevant to questions around contraception or sterilisation that specifically aim to prevent one becoming a parent. However, the question of the exact range of issues to which a framework based on parental action is relevant can be set aside here; the focus in this paper is on the specific issue of sex selection, and this issue does fall within the realm of parental action. The sex selecting agent's situation is one in which the criterion of right parental action is relevant because of the type of project on which the sex selecting agent is embarking. It is a necessary feature of the desire to sex select that it is part of a broader desire to become a parent; you could not want to have a son specifically without wanting, more generally, to be a parent. The sex selecting agent is thus necessarily in the situation of deliberately seeking to have a child; the sex selection decision is part of an overall project of parenthood. As Vehmas has suggested, the decision to procreate itself "puts the potential parents morally in the position of parenthood" [Vehmas italics $].{ }^{13}$ Because the sex selecting agent has deliberately adopted the project of parenthood, he or she has created a situation in which the criterion of right parental action is relevant, despite the fact that no child yet exists. Thus we can justifiably assess the moral permissibility of sex selection using the parenting specific claims articulated above.

Before proceeding to an ethical assessment of sex selection using the parental virtues approach, it is worth noting that this approach avoids the non-identity problem faced by an exclusively harm focused approach such as the procreative liberty framework. Because the parental virtues approach draws on the character of the virtuous parent to determine the moral status of an action rather than on the putative harms associated with the action, the fact that the child resulting from the action is not harmed by it becomes irrelevant. By looking ultimately to a general concept of children's flourishing rather than to a mere absence of harm to this specific child, the parental virtues approach avoids the implausibly low threshold for morally permissible reproduction set by an exclusively harm focused approach.

\section{SECTION 2: AN ARGUMENT AGAINST SEX SELECTION BASED ON THE PARENTAL VIRTUE OF ACCEPTANCE}

Recall from the previous section that virtues reflect facts about human life, or human reproduction and rearing specifically in the case of parental virtues. One such fact of the latter type is the unpredictability of children's characteristics. The unpredictability of the child produced is an intrinsic feature of human reproduction. The set of characteristics that one's child will possess at a particular time is inherently unpredictable. Even if a child's genetic make up was entirely known, the immense complexity of every child's environment necessarily makes his or her characteristics unpredictable to some extent. In the case of most naturally conceived children, for example, we would have no idea which of a range of hair colours the child would have aged eight. Even if the precise genetic determinants of hair colour were known, some unpredictability would always remain; the environmental factors to which the child was exposed (perhaps sun exposure in the hair colour example) would inject a degree of randomness into the characteristic actually displayed. Also contributing to the inherent unpredictability of every child's characteristics are the environmental events that produce traits without any genetic input. A child may, for example, be blinded by an accident or made anaemic by the non-availability of particular foods. So it is an intrinsic feature of a child that his or her characteristics will be, to some extent, unpredictable.

Because a child's characteristics are unpredictable, acceptance is a parental virtue. The flourishing of the child is facilitated by the parent's embracing of the child regardless of his or her specific characteristics. Unless the parents act acceptingly toward the child's characteristics, the child's contentment and self esteem, and the parents' ability to enjoy that child, are all in jeopardy. Thus, just as courage is a human virtue because it is conducive to flourishing in light of the fact that humans are subject to pain and challenge, acceptance is a parental virtue because it is conducive to flourishing in light of the fact that human reproduction inevitably produces a child whose characteristics are unpredictable. Because of the way that children are, the virtuous parent (in part) is one who has the character trait of acceptance with respect to his or her child, an accepting attitude that transcends the child's specific characteristics.

Accepting one's child, regardless of his or her particular current characteristics, is already perceived as a necessary characteristic of the good parent. When someone becomes a parent, we expect him or her to maintain that role regardless of the specific features of his or her child at any particular time. We would think extremely badly, for example, of parents who severed their relationship with their daughter once she developed leukaemia, or even treated their son differently purely on the basis that the blond hair of his childhood had now darkened to brown. Thus the claim that acceptance is a parental virtue is a compelling one, both in terms of its relationship to the fact of unpredictability in reproduction and its consistency with current prevailing attitudes.

The child's sex is a characteristic that falls within the scope of this parental virtue of acceptance. Positing acceptance as a parental virtue does not imply that the virtuous parent is one who passively accepts each and every characteristic of his or 
her child. Hursthouse has argued that the notion of a virtue involves "the idea of the getting things right: in the case of generosity giving the right amount of things for the right reasons on the right occasions to the right people" [Hursthouse's italics] (Hursthouse, ${ }^{12}$ pp 228-9). Similarly the parental virtue of acceptance should not be understood as acceptance of absolutely everything. It need not, for example, imply that a mother should passively accept a child's violence toward her. A complete characterisation of the virtue of acceptance would fully explicate the virtue's scope, that is it would articulate exactly what is involved in getting things right with respect to acceptance. However, such a complete characterisation, although useful, is not necessary for the argument here; our focus on sex selection means that the relevant question is whether the child's sex falls within the scope of the parental virtue of acceptance. We do not need to know all of the types of characteristics that are rightly accepted in order to ethically assess sex selection on the parental virtues framework, only whether or not a child's sex is the type of characteristic toward which the virtuous parent acts with acceptance.

Reflection indicates that sex is indeed a characteristic that falls within the scope of the parental virtue of acceptance. Imagine, for example, that there exists a particular type of bacterial infection that results in a complete change in a child's sex. On infection, girls become normal boys and boys become normal girls. One year old children are susceptible to this sex change pathogen. It seems intuitive that parents who rejected their daughter once she became a son, or vice versa, would act wrongly, just as parents who rejected their child once some other medical condition had radically affected his or her characteristics act similarly wrongly. Such a nonaccepting attitude seems to be a non-parental one; the rejection entails some failure in the parental role. Sex is not the type of characteristic that could possibly justify this failure, thus it seems that a child's sex is within the scope of the parental virtue of acceptance.

Therefore, under the criterion of right parental action and on the basis of the parental virtue of acceptance, sex selection is morally impermissible. In acting on a preference to parent only a child of a particular sex, the sex selecting agent fails to act in accordance with the parental virtue of acceptance. (Whether parents should be morally condemned under the parental virtues framework merely for having this preference is arguable; it is clear, however, that acting on the preference is impermissible under the framework.) The sex selecting agent fails to act in accordance with the parental virtue of acceptance, instead positing a specific characteristic, sex, as relevant to his or her attitude to the child. By sex selecting, the agent puts himself or herself into the parenting role yet fails to act in accordance with that role. The sex selecting agent acts wrongly not because acting on a preference for a child of a particular sex is necessarily inconsistent with being a good parent to the child so produced. That the sex selected child happens to be loved and adequately parented does not preclude condemnation of the sex selection act that brought that child into existence. The wrong is the sex selecting agent's failure to act in accordance with a parental character trait, acceptance, which is intrinsically linked on a general conceptual level to the flourishing of children. Sex selection is wrong because it is not in accordance with the parental virtue of acceptance, regardless of the outcome for a specific child.

\section{SECTION 3: TWO POSSIBLE OBJECTIONS}

A possible objection to this argument against sex selection is that it could be seen as implying that parents are obliged to welcome any child regardless of his or her characteristics. If acceptance is a parental virtue and the right thing to do is what the virtuous parent would do, it seems that parents are morally precluded from, for example, using sex selection to avoid medical conditions or terminating a pregnancy when prenatal diagnosis has indicated severe disability. I do not, however, accept that the argument presented against sex selection commits us to requiring parents to welcome absolutely any child. This is because acceptance is only one in a range of parental virtues. Facts other than every child's necessary unpredictability imply other parental virtues. The fact that human reproduction produces offspring that are long dependent, for example, implies that commitment is a parental virtue. Although she does not use the language of virtue, O'Neill makes this suggestion. ${ }^{14}$ Because there is a range of parental virtues, there is potential for conflict amongst them. Cases in which sex selection would ensure the birth of a child unaffected by a particular medical condition or in which severe disability is diagnosed prenatally are, to my mind, such conflict situations. The parental virtue of acceptance points in one direction, and other parental virtues (such as concern that the child's opportunities exceed a certain level) point in another. In such situations, the virtuous parent might in fact decide, all things considered, to abort a pregnancy on the basis of severe disability or to sex select to avoid a medical condition. This objection thus serves to highlight the fact that the argument of the previous section establishes only a prima facie presumption against sex selection rather than a categorical prohibition. The incompatibility of sex selection with the parental virtue of acceptance prevents sex selection being the choice of the virtuous parent in most cases, but not necessarily all; there may be cases (such as the avoidance of a sex linked condition) where another parental virtue is in tension with acceptance and ultimately overrides it. In a situation of radical inequality between men and women, for example, the parental virtue of acceptance would still apply, counselling against sex selection. It may, however, be in conflict with other parental virtues; it is possible that the ultimate verdict on how the virtuous parent would act will support sex selection. The objection that the argument against sex selection cannot be accepted because it implies that parents are obliged to welcome absolutely any child is thus not compelling; the argument does not involve this implication once acceptance is seen as one of a number of parental virtues.

A second possible objection to the argument presented would be to formulate a case in which a couple uses sex selection to have a girl, but willingly commit themselves to parenting any girl regardless of her other characteristics. These parents do not care whether their daughter develops particular typically feminine social characteristics or pursues particular typically feminine projects; they just want a female child. The objection would be that such sex selecting agents act with appropriate acceptance. I do not believe, however, that this type of case is a forceful objection to the argument presented. On my analysis, embarking on parenthood conditional on one's child's sex is not ethically problematic because it points to some defect in parental attitude that will potentially negatively affect the child's welfare in the future. Rather, I have argued that the sex selection act itself is wrong, because the sex selecting agent fails to act in accordance with the parental virtue of acceptance in a situation in which he or she should so act. Thus, although the accept any girl case is less morally problematic in terms of parental acceptance than cases in which sex selecting parents want not only a girl, but a girl with particular typically feminine characteristics, the parents in the accept any girl case still act wrongly. The wrongness of choosing to parent conditional on sex is not ameliorated by future acts of acceptance; the wrongness of sex selection lies in the sex selection act itself. So neither of these two objections gives us reason to reject the presented argument against sex selection. 


\section{CONCLUSION}

Could the argument presented provide an ethical basis for the HFEA's restrictive position on sex selection? As discussed earlier, the HFEA theoretically sets a high threshold, "the occurrence of serious harms", to be met before state intervention in the reproductive realm can be justified (HFEA, ${ }^{1}$ para 132); according to this framework there must be serious harms associated with sex selection in order to justify any state restriction of access to sex selection technology. Therefore, the HFEA needs more than a compelling argument for the wrongness of sex selection to ethically justify its restrictive position; in the light of its explicit commitment to procreative liberty, the HFEA needs a compelling argument for the harmfulness of sex selection.

This is not provided by the argument presented. Although the argument points to a moral wrong inherent in the sex selecting agent's action, it fails as an ethical foundation for the HFEA's position because the posited wrong in sex selection is not a harm related wrong. Recall the non-identity problem from section 1 . The child produced by sex selection is clearly not harmed by his or her parents choosing to sex select; the child's very existence depends on this parental choice. Thus, although the sex selecting agent acts wrongly on the argument presented, this wrong does not involve a harm. On the argument presented, the sex selecting agent acts wrongly yet harms no one. Thus the state restricting access to sex selection is not justified on the HFEA's own formulation; the serious harms threshold has not been met. So, although the argument presented articulates a wrong in sex selection, the argument would be of little use to the HFEA in any attempt to reconcile its restrictive position on sex selection with its overt commitment to procreative liberty.

The HFEA must either abandon its (arguably superficial) commitment to procreative liberty or revise its restrictive position on sex selection. Sex selection is not intrinsically harmful to the child produced (as indicated by the nonidentity problem) so could only be justifiably prohibited under a harm focused framework such as procreative liberty if it involved significant harms to existing people, which seems unlikely. Looking beyond harm enables other wrongs associated with sex selection to be captured; the incompatibility of the practice with the parental virtue of acceptance is the argument I have presented here. Casting this wider net enables a more comprehensive ethical analysis and gives good reason to abandon an exclusively harm focused approach such as the procreative liberty framework. Sex selection cannot be justifiably restricted on a harm focused approach but looking beyond harm reveals the wrongness of the practice, and provides a justificatory basis for a restrictive policy.

\section{ACKNOWLEDGEMENTS}

I would like to thank Julian Savulescu, Adam Cureton, and the two JME reviewers for helpful comments on earlier drafts.

This work was funded by the Commonwealth Scholarship Commission.

\section{REFERENCES}

1 Human Fertilisation and Embryology Authority. Sex selection: options for regulation, 2003. http://www.hfea.gov.uk/AboutHFEA/Consultations (accessed 27 Jan 2004)

2 Harris J. Sex selection and regulated hatred. J Med Ethics, (in press).

3 Human Fertilisation and Embryology Authority. Sex selection: choice and responsibility in human reproduction: paras 78-80. http:// www.hfea.gov.uk/About HFEA/Consultations/Sex\%20Selectionpdf (accessed 5 Feb 2004).

4 Murray T. What are families for? getting to an ethics of reproductive technology. Hastings Cent Rep 2002;32:41-5.

5 Robertson J. Children of choice. Princeton: Princeton University Press, 1994.

6 Dworkin R. Life's dominion: an argument about abortion and euthanasia. London: HarperCollins, 1993:151-68.

7 Parfit D. Reasons and persons. Oxford: Oxford University Press, 1984, ch 16.

8 Lauritzen P. Pursuing parenthood. Bloomington: Indiana University Press, 1993:63.

9 Steinbock B. A call for ethical boundaries in assisted reproduction. Women's Health Issues 1996;6:144-50.

10 Oakley J. Varieties of virtue ethics. Ratio 1996;9:128-52.

11 Hursthouse R. Normative virtue ethics. In: Crisp R, ed. How should one live? New York: Oxford University Press, 1996:22-3.

12 Hursthouse R. Beginning lives. Oxford: Basil Blackwell, 1987:221.

13 Vehmas S. Assent and selective abortion: a response to Rhodes and Häyry. Camb Q Healthc Ethics 2001; 10:433-40.

$14 \mathrm{O}^{\prime}$ Neill O. Autonomy and trust in bioethics. Cambridge: Cambridge University Press, 2002:63.

11 th European Forum on Quality Improvement in Health Care

26-28 April 2006, Prague, Czech Republic

For further information please go to: www.quality.bmipg.com

Book early to benefit from a discounted delegate rate 